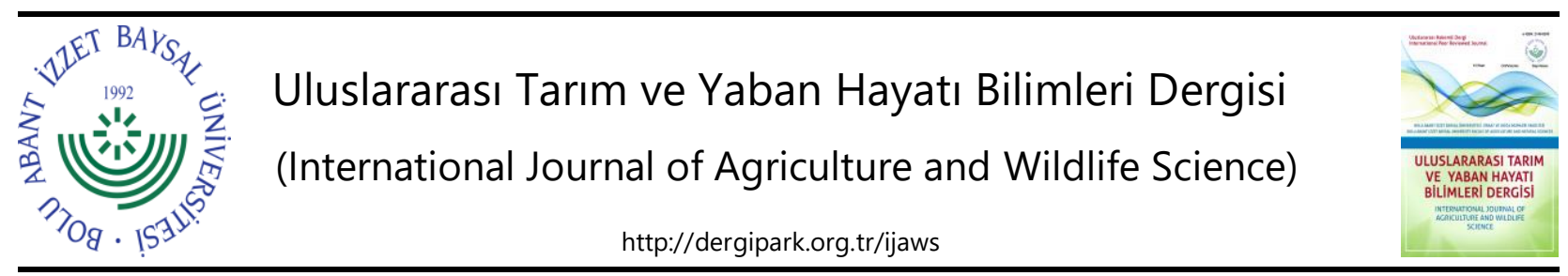

Araştırma Makalesi

\title{
Raf Ömrü Süresince Karayemiş Meyvesinin (Prunus laurocerasus L.) Kalite Özellikleri Üzerine Modifiye Atmosfer Paket ve Aloe vera Uygulamalarının Etkisi
}

\author{
Burhan Öztürk
}

Ordu Üniversitesi, Ziraat Fakültesi, Bahçe Bitkileri Bölümü, Ordu

Geliş tarihi (Received): 17.08.2020 Kabul tarihi (Accepted): 21.09.2020

\begin{abstract}
Anahtar kelimeler:
Çürüme, etilen üretimi, renk, solunum hızı, Prunus laurocerasus

*Sorumlu yazar

burhanozturk55@gmail.com

Özet. Bu araştırma ile soğukta muhafaza $\left(0 \pm 0.5^{\circ} \mathrm{C}\right.$ ve $\left.\% 90 \pm 5\right)$ sonrasında, 3 gün $21 \pm 1^{\circ} \mathrm{C}$ ve $\% 80 \pm 5$ oransal nem koşullarında muhafaza edilen karayemiş meyvesinin kalite özellikleri üzerine modifiye atmosfer paket (MAP) ve Aloe vera jel uygulamalarının etkisini belirlemek hedeflenmiştir. Kontrol grubu meyveler ile kıyaslandığında, 45+3. günde tüm uygulamalarda, 60+3. günde ise MAP içerisindeki meyvelerden önemli derecede daha yüksek solunum hızı ölçülmüştür. 15+3. günde, MAP ve Aloe vera uygulamalarında; $30+3$. günde ise Aloe vera+MAP uygulamasında kontrole göre daha yüksek etilen üretimi elde edilmiştir. Aloe vera+MAP uygulaması ile meyvelerin yumuşaması geciktirilmiştir. Son raf ömrü ölçümünde, MAP ile muamele olmuş meyvelerin $L^{*}$ değerleri daha yüksek bulunmuştur. Aksine tüm uygulamaların hue açı değerleri kontrolden önemli derecede daha düşük belirlenmiştir. $60+3$. günde, Aloe vera uygulamasında en düşük titre edilebilir asitlik ölçülmüştür. MAP içerisinde muhafaza edilen meyvelerin daha az çürüdüğü görülmüştür. Sonuç olarak MAP içerisinde muhafaza edilen meyvelerin raf ömrü süresince daha az kalite kaybına uğradığı ortaya konmuştur.
\end{abstract}

\section{Effects of Modified Atmosphere Packaging and Aloe vera Treatments on Quality Traits of Cherry Laurel Fruit (Prunus laurocerasus L.) During Shelf Life}

\section{Keywords:}

Color, decay, ethylene production, respiration rate, Prunus laurocerasus,

\begin{abstract}
This research aimed to assess the effect modified atmosphere packaging (MAP) and Aloe vera gel treatments on the quality traits of cherry laurel fruit kept at $21 \pm 1{ }^{\circ} \mathrm{C}$ and $80 \pm 5 \%$ relative humidity for 3 days after cold storage $\left(0 \pm 0.5{ }^{\circ} \mathrm{C}\right.$ and $\left.\% 90 \pm 5\right)$. Compared to the control, in all treatment on the $45+3$ day, in fruit kept in MAP on the $60+3$ day, respiration rate was higher. In MAP and Aloe vera treatments on the $15+3$ day, in Aloe vera+MAP treatment on the $30+3$ day, ethylene production was higher obtained than control treatments. The softening of fruit was delayed by Aloe vera +MAP treatment. At last measurement of shelf life, $L^{*}$ values of MAP-treated fruit was higher than control. But, hue angle of Aloe vera and MAP-treated fruit was lower shown. On the $60+3$ day, the lowest titratable acidity was measured in Aloe vera treatment. It was observed that fruit stored in MAP were less rotten. As a result, it was revealed that fruit stored in MAP were exposed less quality losses of during shelf life.
\end{abstract}




\section{GíRiş}

Karayemiş meyvesi, Türkiye'de özellikle Doğu Karadeniz Bölgesi'nde, Toros Dağları'nda, Marmara'nın doğusu ve Ege Bölgesi'nde doğal olarak yetişen, son yıllarda yapılan seleksiyon çalışmaları ile elde edilen ümitvar tipler ile kültürü yapılan yüksek besin içeriğine sahip her dem yeşil bir meyve türüdür. Taze tüketiminin yanında, pekmez, reçel, marmelat, kurutulmuş, salamura edilmiş ve meyve suyu gibi işlenmiş olarak da tüketilmektedir. Ayrıca halk arasında tıbbı bitki olarak bilinmektedir. Taze meyveleri ve tohumları birçok hastalığın tedavisinde geleneksel olarak kullanılmaktadır (İslam, 2002; Kolaylı ve ark., 2003; Sülüşoğlu ve Çavuşoğlu, 2009; Kasim ve ark., 2011; Yazıcı ve ark., 2011; Ozturk ve ark., 2017).

Karayemiş meyvesinin besin içeriği üzerine yapılan çalışmalarda, meyvenin içerdiği zengin fenolik bileşiklere bağlı olarak yüksek antioksidan kapasitesine sahip olduğu ortaya konmuştur (Ayaz, 2001; Var ve Ayaz, 2004; Yazıcı ve ark., 2011; Ozturk ve ark., 2019a; Celik ve ark., 2020). Karayemişin insan beslenmesi açısından öneminin belirlenmesinden sonra, kültüre alınmasına ve yaygınlaştırılmasına yönelik olarak birçok çalışma yürütülmüştür (Karadeniz ve Kalkısım, 1996; Sulusoglu, 2011; Islam ve Deligöz, 2012).

Karayemiş meyvesinin seleksiyonu, çoğaltılması ve besin içeriği konusunda pek çok araştırma yapılmış olmasına rağmen, muhafazası konusunda oldukça sınırlı sayıda hasat sonu, raf ömrü süresince meyve kalite özelliklerinin belirlenmesi konusunda ise literatürde bir çalışmaya rastlanmamıştır. Bilindiği gibi meyve ve sebzelerin derim sonrası soğukta muhafaza ve raf ömrü süresince meyve kalitelerinin korunması gerekmekte olup, bu da uygun şartlarda muhafaza başta olmak üzere derim sonrası farklı uygulamalar ve teknolojiler ile sağlanabilmektedir. Derim sonrası teknolojilerin başında modifiye atmosfer paketleme (MAP) gelmektedir. Buna ilave olarak son yıllarda kitosan, aljinat ve Aloe vera gibi yenilebilir film kaplamalarda kullanılmaktadır. Bu araçlar ile temel amaç, solunumu yavaşlatmak ve olgunlaşmada etkili olan metabolik olayları yavaşlatmaktır (MartinezRomero ve ark., 2006; Castillo ve ark., 2010; Ozturk ve ark., 2019a).

Kullanılan paketleme malzemesinin gaz difüzyon özellikleri ve bitki dokusunun solunum hızının bir sonucu olarak ambalajlar içerisinde atmosferin gaz değişimi sağlanmaktadır (Zhang ve ark., 2003). Kaplama uygulamaları ile meyve kabuk yüzeyinde yarı geçirgen bir tabaka oluşturulmakta ve nem kaybı, solunum ve oksidatif reaksiyonlar yavaşlatılmaktadır. Bunların sonucunda da meyvede doğal olgunlaşma süreci geciktirilmektedir (Vargas ve ark., 2008). Özellikle gıda üretiminde sentetik kimyasal maddeler konusundaki çevresel ve sağlıkla ilgili hassasiyetlerin artması, Aloe vera gibi doğal maddelerin kullanımına olan ilgiyi artırmaktadır (Vieira ve ark., 2016). Aloe vera, sofralık üzüm, nektarin ve kiraz gibi meyvelerde mikroorganizma çoğalmasını azaltmak, oksidatif kararmayı geciktirmek, solunum hızı ve meyve olgunlaşmasını kontrol etmek, sertlik ve nem kaybını engellemek için kullanılmıştır (Martinez-Romero ve ark., 2006; Ahmed ve ark., 2009; Castillo ve ark., 2010).

Yukarda verilen bilgilerin ışığında bu çalışmada, MAP ve Aloe vera uygulamalarının karayemiş meyvesinin raf ömrü süresince meyve kalite özellikleri üzerine olan etkilerinin yanında solunum hızı ve etilen sentezi gibi derim sonrası fizyolojisiyle ilgili parametrelerde meydana gelen değişimin belirlenmesi amaçlanmıştır.

\section{MATERYAL VE METOT}

\section{Bitkisel Materyal ve Denemenin Kurulmast}

Çalışmada, seçilmiş O-44 genotipine ait karayemiş meyveleri kullanılmıştır. Meyveler, \%15.0 SÇKM ve 3.4 newton (N) meyve sertliği safhasında (30 Temmuz 2015) elle hasat edilmiştir. Meyveler, 5 kg kapasiteli plastik kasalara (Plastaş, Düzce) yerleştirilmiş ve akabinde $10 \pm 1.0^{\circ} \mathrm{C}$ ve $\% 80 \pm 5.0$ oransal nem koşullarında soğutuculu araç ile 1 saat içerisinde Ordu Üniversitesi Ziraat Fakültesi Bahçe Bitkileri Bölümü laboratuvarına transfer edilmiştir.

Laboratuvarda aynı büyülükte, homojen renklenmiş, sağlam, bütünlük arz eden ve hastalık belirtisi olmayan salkımlar deneme için seçilmiştir. Illk olarak meyveler iki gruba ayrılmıştır. Illk grup yalnızca saf suya, diğer grup \% $33^{\prime}$ lük Aloe vera jeline (Forever living products, Türkiye) 5 saniye süre ile batırılmıştır. Meyveler, oda koşullarında $\left(21 \pm 1^{\circ} \mathrm{C}\right.$ ve $\% 80 \pm 5$ oransal nemde) kurutma kâğıdı üzerinde 1 saat süre ile kurutulmuştur. Akabinde meyveler tekrar 2 gruba ayrılmıştır. Bunların bir yarısı MAP (Xtend ${ }^{\circledR}$ (815-CH97/a, StePac, Tefen, Israil) içerisine yerleştirilirken, diğer yarısı ambalaj içerisine yerleştirilerek denemede kontrol, MAP, Aloe vera ve Aloe vera+MAP olmak üzere 4 farklı uygulama belirlenmiştir. Meyveler her birinde yaklaşık $750 \mathrm{~g}$ meyve olacak şekilde plastik kasalara (39 × $29 \times 21 \mathrm{~cm}$, Plastas, Türkiye) yerleştirilmiştir. Daha sonra meyveler $4 \pm 0.5^{\circ} \mathrm{C}$ ve $\% 90 \pm 5$ oransal nem koşullarında, 24 saat soğuk hava ile ön soğutmaya maruz bırakılmıştır. Ön soğutmadan sonra MAP ambalajlarının ağızları klips ile kapatılarak, $0 \pm 0.5^{\circ} \mathrm{C}$ ve $\% 90 \pm 5$ oransal nem koşullarında 60 gün muhafaza edilmiştir. Meyveler, hasat dönemine ilave olarak, 15, 30, 45 ve 60 . günlerde soğuk odadan çıkartılmış ve 3 gün süresince $21 \pm 1^{\circ} \mathrm{C}$ ve $\% 80 \pm 5$ oransal nemde bekletildikten sonra ölçüm ve analizleri yapılmıştır. Her bir ölçüm döneminde her bir uygulama için 3 kasa analiz edilmiş ve her bir kasa tekerrürü temsil etmiştir. 


\section{Solunum Hızı, Etilen Üretimi ve Meyve Sertliği}

Solunum ölçümü için ilk olarak meyveler (10 meyve), 2 L'lik gaz sızdırmaz kap içerisine yerleştirilmiş ve 1 saat bekletilmiştir. Daha sonra gaz sızdırmaz kaba bağlı olan gaz sensörü (Vernier, Oregon, Amerika) vasıtasıyla, meyvelerin ortama verdiği $\mathrm{CO}_{2}$ konsantrasyonu ölçülmüştür. $\mathrm{CO}_{2}$ miktarı esas alınarak meyvelerin solunum hızı $\mathrm{mL} \mathrm{CO} 2 \mathrm{~kg}^{-1} \mathrm{~h}^{-1}$ olarak hesaplanmıştır. Etilen üretimi içinde benzer şekilde gaz sızdırmaz ortamdan $1 \mathrm{~mL}$ gaz örneği, gaz sızdırmaz şırınga ile çekilmiş ve gaz kromatografisine (QP2010 Ultra, Shimadzu, Japonya) enjekte edilmiştir. Etilen üretim miktarı, $\mu \mathrm{L} \mathrm{C}_{2} \mathrm{H}_{4} \mathrm{~kg}^{-1} \mathrm{~h}^{-1}$ olarak ifade edilmiştir. Meyve eti sertliği (10 meyvede), tekstür analiz cihazında (TA-TX Plus, Stable Microsystems, Godalming, İngiltere) belirlenmiştir. Ölçümlerde 2.0 mm'lik uç, maksimum $50 \mathrm{~N}$ yük ve $10 \mathrm{~mm} \mathrm{~s}^{-1}$ hız ile $4 \mathrm{~mm}$ meyve etine batııımıştır. Ölçülen değer, Newton (N) olarak ifade edilmiştir (Ozturk ve ark., 2019b).

\section{Renk Özellikleri}

Bir renk ölçer (Konica-Minolta, model CR-400, Japan) vasıtasıyla meyve kabuk yüzeyinde (her bir tekerrürde 20 meyvede), $L^{*}$, kroma ve hue açısı değerleri belirlenmiştir. Üç boyutlu renk dairesi, $L^{*}, a^{*}$ ve $b^{*}$ değerlerinin yardımıyla tanımlanmıştır. Kroma değeri, $\left.C^{*}=\left(a^{* 2}+b^{* 2}\right)^{1 / 2}\right]$, hue açısı değeri ise $h^{\circ}=\tan ^{-1} b^{*} / a^{*}$ formülü ile hesaplanmıştır.

\section{Suda Çözünebilir Kuru Madde (SÇKM) ve Titre Edilebilir Asitlik}

Her bir uygulamaya ait her bir tekerrürden yeterince meyve alınmış, çekirdekleri elle çıkarılmış ve elektrikli karıştırıcı (HR1855/70, Philips, Türkiye) ile meyve eti parçalanmıştır. Elde edilen meyve posası tülbentten geçirilerek meyve suyu elde edilmiştir. SÇKM için, meyve suyundan pipet yardımı ile $1 \mathrm{~mL}$ meyve suyu alınmış ve dijital refraktometreye damlatılmış, ekranda okunan değer \% olarak kaydedilmiştir. Titre edilebilir asitlik için, $10 \mathrm{~mL}$ meyve suyu üzerine $10 \mathrm{~mL}$ saf su ilave edilmiş ve elde edilen meyve suyu $0.1 \mathrm{~N} \mathrm{NaOH}$ ile pH 8.2 olana kadar titre edilmiştir. Asitlik, titrasyonda harcanan $\mathrm{NaOH}$ miktarı esas alınarak, g malik asit $100 \mathrm{~g}^{-1}$ olarak hesaplanmıştır (Ozturk ve Ozer, 2019).

\section{Çürüme Oranı ve Çürüme Indeksi}

Çürüme, görsel olarak değerlendirilmiş olup, meyve kabuk yüzeyinde misel gelişimi olmuş meyveler çürümüş kabul edilmiştir. Çürüme oranı= [(toplam meyve sayısı-sağlam meyve sayısı)/toplam meyve sayısı] x 100 formülü ile bulunmuştur. Çürüme indeksi Selcuk ve Erkan (2014)'nın bildirdiği gibi 1-5 skalasında değerlendirilmiştir. Skalada $1=$ hiç çürüme olmadığını, 2= \% 25 çürümeyi, 3= \% 50 çürümeyi, 4= \% 75 çürümeyi ve 5= meyvenin tamamen çürüdüğünü ifade etmektedir.

\section{Istatistik Analizler}

Denemede, verilerin normallik kontrolü Kolmogorov-Smirnov, varyansın homojenliği ise Levene testi ile belirlenmiştir. Elde edilen veriler varyans analizi (ANOVA) ile analiz edildikten sonra muameleler arasındaki önemlilik düzeyi Tukey çoklu karşılaştırma testi $(p<0.05)$ ile belirlenmiştir. İstatistik analizler SAS paket programında (SAS 9.1 versiyon, ABD) yapılmıştır.

\section{BULGULAR VE TARTIŞMA}

\section{Solunum Hızı, Etilen Üretimi ve Meyve Sertliği}

Araştırmada, solunum hızı, etilen üretimi ve meyve sertliği bakımından uygulamalar arasında önemli farklııklar belirlenmiştir (Çizelge 1). Solunum hızı 30+3. günde, MAP ve Aloe vera; $45+3$. günde tüm uygulamalarda ve $60+3$. günde ise MAP içerisindeki karayemiş meyvelerinde kontrol meyvelerine kıyasla daha yüksek ölçülmüştür. Etilen üretimi, $15+3$ günde MAP ve Aloe vera; $30+3$. günde ise yalnızca Aloe vera+MAP uygulamasında kontrolden önemli seviyede yüksek bulunmuştur. Meyve sertliği bakımından 15. günün raf ömründe, Aloe vera+MAP uygulamasında kontrole kıyasla önemli seviyede daha yüksek sertlik ölçülmüştür. Aksine yalnızca MAP uygulanmış olan meyvelerden ise hem kontrol hem de diğer uygulamalara kıyasla daha düşük sertlik tespit edilmiştir. 30 ve 45+3. günde ise Aloe vera+MAP ile muamele olmuş karayemiş meyvelerinin sertlik değerlerinin, kontrol ve diğer uygulamalara kıyasla önemli derecede daha yüksek olduğu görülmüştür (Çizelge 1).

Hasat edilen meyvelerde, kalite kayıpları kaçınılmazdır. Özellikle meyvelerde artan solunum hızı ve etilen üretimi ile meyvelerde kalite kayıpları hızlanmaktadır. Fakat bu kayıpların azaltılması, derim sonrası kaplama ve MAP gibi hasat sonrası bazı teknikler ile mümkün olabilmektedir. Aloe vera uygulaması, meyve kabuğunun gaz difizyonuna karşı direncini artırarak solunumu yavaşlatmaktadır (Banks ve ark., 1993). Çalışmamızda solunum hızı ve etilen üretimi üzerine Aloe vera ve MAP uygulamalarının belirgin bir etkisi saptanmamıştır. Hâlbuki Carrillo- 
Lopez ve ark. (2000) ve Guillen ve ark. (2013) Aloe vera uygulamasının solunum ve etilen üretim hızını yavaşlattığını bildirmiştir. Çalışmamızda, beklenildiği gibi solunum hızı ve etilen üretimi MAP ve Aloe vera uygulamaları ile geciktirilememiştir. Çalışılan meyve türünün farklı olması, bulgular arasındaki bu farklılığın temel nedenleri arasında olabilir.

Çalışmamızda MAP ile kombine edilen Aloe vera uygulamasının et sertliğinde meydana gelen yumuşamayı geciktirdiği görülmüştür. Benzer şekilde pek çok meyve türünde kaplama uygulamaları ile meyve eti sertliğinde meydana gelen yumuşama geciktirilmiştir (Martinez-Romero ve ark., 2006; Ahmed ve ark., 2009; Castillo ve ark., 2010). Martinez-Romero ve ark. (2006) Aloe vera uygulamasının pektin metil esteraz ve poligalukturonaz gibi hücre duvarını parçalayan enzim aktivitesini düzenleyerek meyve eti sertliğini muhafaza ettiğini bildirmişlerdir.

\section{Renk Özellikleri}

$L^{*}$ değeri bakımından, 45 ve 60 . gün raf ömrü ölçümlerinde uygulamalar arasında önemli farklııılar belirlenmiştir. 45+3. günde yalnızca MAP; 60+3. günde ise Aloe vera+MAP uygulanmış karayemiş meyvelerinden kontrole kıyasla önemli derecede daha yüksek $L^{*}$ değeri ölçülmüştür. $15+3$. günde Aloe vera uygulanmış meyvelerde; $30+3$ ve $45+3$. günde tüm uygulamalarda; $60+3$. günde ise $A$ loe vera uygulamasından kontrole göre daha yüksek kroma değeri tespit edilmiştir. $15+3$ ve $60+3$. gün raf ömründe ise tüm uygulamalarda, kontrole kıyasla daha düşük hue açısı değeri belirlenmiştir. 30+3. günde MAP içerisinde muhafaza edilmiş tüm meyvelerde; 45+3. günde ise Aloe vera+MAP uygulanmış karayemiş meyvelerinden kontrole kıyasla önemli derecede daha düşük hue açısı değeri saptanmıştır (Çizelge 2).

Çizelge 1. Raf ömrü süresince karayemiş meyvesinin solunum hızı, etilen üretimi ve meyve sertliği değişimi. Table 1. Change of respiration rate, ethylene production and fruit firmness of cherry laurel fruit during shelf life.

\begin{tabular}{|c|c|c|c|c|c|}
\hline \multirow[t]{2}{*}{ Uygulama } & \multicolumn{5}{|c|}{ Solunum hızı (mL CO $\left.2 \mathrm{~kg}^{-1} \mathrm{~h}^{-1}\right)$} \\
\hline & $0+3$ & $15+3$ & $30+3$ & $45+3$ & $60+3$ \\
\hline Kontrol & 53.61 & $29.95 \mathrm{a}$ & $24.91 b$ & $20.90 \mathrm{~b}$ & $19.52 \mathrm{~b}$ \\
\hline MAP & 53.61 & $30.50 a$ & $27.44 \mathrm{a}$ & $26.04 \mathrm{a}$ & $24.14 a$ \\
\hline Aloe vera & 53.61 & 29.29 a & $28.04 \mathrm{a}$ & $24.52 \mathrm{a}$ & $20.06 \mathrm{~b}$ \\
\hline \multirow[t]{2}{*}{ Aloe vera + MAP } & 53.61 & $30.93 a$ & $24.23 \mathrm{~b}$ & $23.75 \mathrm{a}$ & $22.91 \mathrm{a}$ \\
\hline & \multicolumn{5}{|c|}{ Etilen Üretimi $\left(\mu \mathrm{L} \mathrm{C}_{2} \mathrm{H}_{4} \mathrm{~kg}^{-1} \mathrm{~h}^{-1}\right)$} \\
\hline Kontrol & 0.132 & $0.154 \mathrm{c}$ & $0.090 \mathrm{~b}$ & $0.106 \mathrm{ab}$ & $0.098 \mathrm{a}$ \\
\hline MAP & 0.132 & $0.197 b$ & $0.115 \mathrm{ab}$ & $0.092 b$ & $0.092 \mathrm{a}$ \\
\hline Aloe vera & 0.132 & $0.232 a$ & $0.120 \mathrm{ab}$ & $0.114 a b$ & $0.110 a$ \\
\hline \multirow[t]{2}{*}{ Aloe vera+MAP } & 0.132 & $0.157 \mathrm{c}$ & $0.139 a$ & $0.129 \mathrm{a}$ & $0.099 \mathrm{a}$ \\
\hline & \multicolumn{5}{|c|}{ Meyve Sertliği (N) } \\
\hline Kontrol & 2.17 & $2.01 \mathrm{~b}$ & $1.70 \mathrm{~b}$ & $1.64 \mathrm{~b}$ & $1.45 \mathrm{a}$ \\
\hline MAP & 2.17 & $1.75 \mathrm{c}$ & $1.68 \mathrm{~b}$ & $1.56 \mathrm{~b}$ & $1.40 \mathrm{a}$ \\
\hline Aloe vera & 2.17 & $2.03 \mathrm{~b}$ & $1.63 b$ & $1.60 \mathrm{~b}$ & $1.43 a$ \\
\hline Aloe vera $+\mathrm{MAP}$ & 2.17 & $2.61 \mathrm{a}$ & $1.96 \mathrm{a}$ & $1.84 \mathrm{a}$ & $1.49 \mathrm{a}$ \\
\hline
\end{tabular}

Aynı sütunda aynı harfle gösterilen ortalamalar arasında Tukey testine göre fark yoktur $(p<0.05)$.

Farklı meyve türlerinde yapılan çalışmalarda (Castillo ve ark., 2012; Guillen ve ark., 2013), kaplama ve MAP uygulamaları ile renklenmenin geciktirildiği bildirilmesine rağmen, çalışmamızda bulguları destekler sonuç elde edilmemiştir. Aksine kırmızı renk gelişimini gösteren hue açısı değeri MAP ve Aloe vera+MAP uygulamasında, kontrolden daha düşük çıkmıştır. Bu da uygulamaların kırmızı renk gelişimini teşvik ettiğini göstermektedir.

\section{Suda Çözünebilir Kuru Madde (SÇKM) ve Titre Edilebilir Asitlik}

Karayemiş meyvelerinde raf ömrü süresinin ilerlemesine bağlı olarak SÇKM içeriği artış göstermiştir. Aksine meyvelerin titre edilebilir asitlik içeriğinde azalış görülmüştür. SÇKM içeriği bakımından, uygulamalar arasında yalnızca 15+3. günde önemli farklılıklar belirlenmiş olup, Aloe vera uygulanmış meyvelerde, kontrole kıyasla önemli seviyede daha düşük değerler belirlenmiştir. $15+3$. günde Aloe vera; $30+3$ ve $60+3$. günde MAP; $45+3$. günde ise MAP ve Aloe vera uygulamalarına ait meyvelerin asitlik içeriğinin, kontrole kıyasla önemli derecede daha yüksek olduğu tespit edilmiştir (Çizelge 3). 
Çizelge 2. Raf ömrü süresince karayemiş meyvesinin $L^{*}$, kroma ve hue açısı değeri değişimi. Table 2. Change of $L^{*}$, chroma and hue angle values of cherry laurel fruit during shelf life.

\begin{tabular}{|c|c|c|c|c|c|}
\hline \multirow[t]{2}{*}{ Uygulama } & \multicolumn{5}{|c|}{$\mathbf{L}^{*}$} \\
\hline & $0+3$ & $15+3$ & $30+3$ & $45+3$ & $60+3$ \\
\hline Kontrol & 24.22 & 24.78 a & $25.08 \mathrm{a}$ & $25.44 \mathrm{~b}$ & $26.59 \mathrm{~b}$ \\
\hline MAP & 24.22 & $25.47 \mathrm{a}$ & $25.90 \mathrm{a}$ & 26.70 a & $26.99 a b$ \\
\hline Aloe vera & 24.22 & $25.53 \mathrm{a}$ & $25.68 \mathrm{a}$ & $25.81 \mathrm{ab}$ & $26.23 \mathrm{~b}$ \\
\hline \multirow[t]{2}{*}{ Aloe vera+MAP } & 24.22 & $24.59 \mathrm{a}$ & $25.58 \mathrm{a}$ & $26.33 \mathrm{ab}$ & $27.70 \mathrm{a}$ \\
\hline & \multicolumn{5}{|c|}{ Kroma } \\
\hline Kontrol & 8.67 & $4.13 c$ & $4.30 \mathrm{~b}$ & $4.14 \mathrm{~b}$ & $3.40 \mathrm{~b}$ \\
\hline MAP & 8.67 & $9.33 a b$ & $7.86 \mathrm{a}$ & $7.16 \mathrm{a}$ & $3.27 \mathrm{~b}$ \\
\hline Aloe vera & 8.67 & $8.60 \mathrm{~b}$ & $8.44 \mathrm{a}$ & $6.05 a$ & $5.20 \mathrm{a}$ \\
\hline \multirow[t]{2}{*}{ Aloe vera+MAP } & 8.67 & $10.40 \mathrm{a}$ & $7.64 \mathrm{a}$ & $6.83 a$ & $3.89 a b$ \\
\hline & \multicolumn{5}{|c|}{ Hue açısı } \\
\hline Kontrol & 16.59 & $19.51 \mathrm{a}$ & $22.75 \mathrm{a}$ & $22.94 \mathrm{a}$ & $27.59 \mathrm{a}$ \\
\hline MAP & 16.59 & $15.85 c$ & $19.65 \mathrm{~b}$ & $21.69 \mathrm{a}$ & $25.67 \mathrm{~b}$ \\
\hline Aloe vera & 16.59 & $17.92 \mathrm{~b}$ & $22.27 \mathrm{a}$ & $22.86 \mathrm{a}$ & $25.36 \mathrm{~b}$ \\
\hline Aloe vera $+\mathrm{MAP}$ & 16.59 & $14.24 \mathrm{~d}$ & $17.13 c$ & $18.41 \mathrm{~b}$ & $20.93 c$ \\
\hline
\end{tabular}

Aynı sütunda aynı harfle gösterilen ortalamalar arasında Tukey testine göre fark yoktur $(p<0.05)$.

Çalışmamızda SÇKM içeriği üzerine genel olarak uygulamaların önemli bir etkisi saptanmıştır. Nitekim farkı meyve türlerinde yapılan çalışmalarda, MAP ve Aloe vera uygulanmış meyvelerin SÇKM'sinin uygulanmayan meyvelerin SÇKM'sinden farksız olduğunu bildiren araştırma sonuçları da (Cantin ve ark., 2008; Guillen ve ark., 2013) bulunmaktadır. Fakat asitliğin MAP uygulamasında kontrol ve diğer uygulamalara kıyasla daha yüksek olduğu görülmüştür. MAP uygulaması, karayemiş meyvelerinde olgunlaşmayı geciktirmiş, Aloe vera uygulaması ise olgunlaşmayı teşvik etmiş olabilir. Bu yüzden geciken olgunlaşmaya bağlı olarak yalnızca MAP uygulanmış meyvelerin titre edilebilir asitlik düzeyi daha yüksek çıkmış olabilir.

Çizelge 3. Raf ömrü süresince karayemiş meyvesinin SÇKM ve asitlik değişimi.

Table 3. Change of SSC and titratable acidity of cherry laurel fruit during shelf life.

\begin{tabular}{lccccc}
\hline Uygulama & \multicolumn{5}{c}{ SÇKM (\%) } \\
\cline { 2 - 6 } & $0+3$ & $15+3$ & $30+3$ & $45+3$ & $60+3$ \\
\hline Kontrol & 23.7 & $25.6 \mathrm{a}$ & $25.9 \mathrm{a}$ & $26.7 \mathrm{a}$ & $28.0 \mathrm{a}$ \\
MAP & 23.7 & $24.4 \mathrm{ab}$ & $25.7 \mathrm{a}$ & $26.8 \mathrm{a}$ & $27.2 \mathrm{a}$ \\
Aloe vera & 23.7 & $22.0 \mathrm{c}$ & $26.5 \mathrm{a}$ & $26.9 \mathrm{a}$ & $28.3 \mathrm{a}$ \\
Aloe vera+MAP & 23.7 & $23.2 \mathrm{bc}$ & $24.8 \mathrm{a}$ & $26.1 \mathrm{a}$ & $29.1 \mathrm{a}$ \\
\hline Kontrol & \multicolumn{7}{c}{ Titre Edilebilir Asitlik (\% malik asit) } & $0.71 \mathrm{c}$ & $0.65 \mathrm{~b}$ \\
MAP & 1.08 & $0.95 \mathrm{bc}$ & $0.84 \mathrm{~b}$ & $0.86 \mathrm{a}$ & $0.74 \mathrm{a}$ \\
Aloe vera & 1.08 & $1.02 \mathrm{ab}$ & $0.93 \mathrm{a}$ & $0.80 \mathrm{ab}$ & $0.55 \mathrm{c}$ \\
Aloe vera+MAP & 1.08 & $1.04 \mathrm{a}$ & $0.85 \mathrm{~b}$ & $0.76 \mathrm{bc}$ & $0.65 \mathrm{~b}$ \\
\hline
\end{tabular}

Aynı sütunda aynı harfle gösterilen ortalamalar arasında Tukey testine göre fark yoktur $(p<0.05)$.

\section{Çürüme Oranı ve Çürüme Indeksi}

Hasat dönemindeki raf ömrü ölçümlerinde (0+3. gün) meyvelerde çürüme belirlenmemiştir. $15+3$ ve $60+3$. gün ölçümünde, MAP ve Aloe vera uygulanmış meyvelerin çürüme oranı ve çürüme indeksinin, kontrole kıyasla önemli seviyede daha düşük olduğu görülmüştür. $30+3$. gündeMAP uygulanmış meyvelerde; $45+3$. günde ise yalnızca MAP uygulamasında, kontrole kıyasla önemli seviyede daha düşük çürüme oranı belirlenmiştir (Çizelge 2).

Çürüme, yaş meyve ve sebzelerde raf ömrü süresince meydana gelen en önemli kayıpların başında gelmektedir. Antimikrobiyal özelliğinden dolayı Aloe vera uygulamasının derim sonrası meyve ve sebzelerde çürüme oranını azaltmak amacıyla kullanılabileceği bildirilmiştir (Serrano ve ark., 2006; Kahramanoğlu ve ark., 2019). Genel olarak çalışmamızda Aloe vera uygulaması karayemiş meyvesinin çürümesini geciktirmiştir. Aynı 
zamanda MAP ve Aloe vera+MAP uygulamalarından elde edilen çürüme oranı daha önceki bulgular (Cantin ve ark., 2008; Steffens ve ark., 2018) ile uyumlu olarak kontrolden daha düşük çıkmıştır.

Çizelge 4. Raf ömrü süresince karayemiş meyvesinin çürüme oranı ve çürüme indeksi değişimi. Table 4. Change of decay rate and decay index of cherry laurel fruit during shelf life.

\begin{tabular}{lccccc}
\hline Uygulama & \multicolumn{5}{c}{ Çürüme oranı (\%) } \\
\cline { 2 - 6 } & $0+3$ & $15+3$ & $30+3$ & $45+3$ & $60+3$ \\
\hline Kontrol & 0.00 & $1.71 \mathrm{a}$ & $2.23 \mathrm{~b}$ & $3.23 \mathrm{~b}$ & $7.41 \mathrm{a}$ \\
MAP & 0.00 & $0.10 \mathrm{~b}$ & $1.33 \mathrm{c}$ & $2.44 \mathrm{c}$ & $3.34 \mathrm{c}$ \\
Aloe vera & 0.00 & $0.30 \mathrm{~b}$ & $3.25 \mathrm{a}$ & $6.25 \mathrm{a}$ & $7.33 \mathrm{a}$ \\
Aloe vera+MAP & 0.00 & $0.30 \mathrm{~b}$ & $1.01 \mathrm{c}$ & $3.64 \mathrm{~b}$ & $4.48 \mathrm{~b}$ \\
\hline \multicolumn{7}{c}{ Çürüme indeksi } \\
\hline Kontrol & 1 & $2 \mathrm{a}$ & $2 \mathrm{a}$ & $2 \mathrm{~b}$ & $3 \mathrm{a}$ \\
MAP & 1 & $1 \mathrm{~b}$ & $1 \mathrm{~b}$ & $1 \mathrm{c}$ & $1 \mathrm{c}$ \\
Aloe vera & 1 & $1 \mathrm{~b}$ & $2 \mathrm{a}$ & $3 \mathrm{a}$ & $2 \mathrm{~b}$ \\
Aloe vera+MAP & 1 & $1 \mathrm{~b}$ & $1 \mathrm{~b}$ & $3 \mathrm{a}$ & $1 \mathrm{c}$ \\
\hline Ayn
\end{tabular}

Aynı sütunda aynı harfle gösterilen ortalamalar arasında Tukey testine göre fark yoktur $(p<0.05)$.

\section{SONUÇ}

Sonuç olarak meyvelerde çürümenin geciktirilmesi bakımından Aloe vera ve MAP uygulamasının önemli bir derim sonrası araç olarak kullanılabileceği ifade edilebilir. Fakat meyve et sertliğinin korunmasında ise MAP ve Aloe vera uygulamalarının kombine etkisinin daha iyi sonuçlar verdiği söylenebilir. Çalışmamızda Aloe vera jeli tek konsantrasyonda uygulanmıştır. Farklı konsantrasyonların etkisinin belirlenmesi için yeni çalışmaların planlanması gerekmektedir.

\section{ÇIKAR ÇATIŞMASI}

Herhangi bir çıkar çatışması yoktur.

\section{YAZAR KATKISI}

Burhan Öztürk; Çalışmanın tasarlanması, hasat işleminin gerçekleştirilmesi, laboratuvar ölçüm ve analizlerinin yürütülmesi, elde edilen verilerin değerlendirilmesi ve makale yazma işlemlerinin tümünü gerçekleştirmiştir.

\section{TEŞEKKÜR}

Bu araştırma Ordu Üniversitesi Bilimsel Araştırma Projeleri Koordinasyon Birimi tarafından TF-1508 kodlu proje ile desteklenmiştir.

\section{KAYNAKLAR}

Ahmed, M. J., Singh, Z., \& Khan, A. S. (2009). Postharvest Aloe vera gel-coating modulates fruit ripening and quality of 'Arctic Snow' nectarine kept in ambient and cold storage. International Journal of Food Science \& Technology, 44(5), 1024-1033.

Ayaz, F. A. (2001). Changes in phenolic acids of cherry laurel [Laurocerasus officinalis Oxygemmis] fruit during maturation. Acta Biologica Cracoviensia. Series Botanica, 43, 23-46.

Banks, N. H., Dadzie, B. K., \& Cleland, D. J. (1993). Reducing gas exchange of fruits with surface coatings. Postharvest Biology and Technology, 3(3), 269-284.

Cantín, C. M., Crisosto, C. H., \& Day, K. R. (2008). Evaluation of the effect of different modified atmosphere packaging box liners on the quality and shelf life of 'Friar' plums. HortTechnology, 18(2), 261-265.

Carrillo-Lopez, A., Ramirez-Bustamante, F., Valdez-Torres, J. B., Rojas-Villegas, R., \& Yahia, E. M. (2000). Ripening and quality changes in mango fruit as affected by coating with an edible film. Journal of Food Quality, 23(5), 479-486. 
Castillo, S., Navarro, D., Zapata, P. J., Guillén, F., Valero, D., Serrano, M., \& Martínez-Romero, D. (2010). Antifungal efficacy of Aloe vera in vitro and its use as a preharvest treatment to maintain postharvest table grape quality. Postharvest Biology and Technology, 57(3), 183-188.

Castillo, S., Navarro, D., Zapata, P. J., Guillén, F., Valero, D., Martínez-Romero, D., \& Serrano, M. (2012). Using Aloe vera as a preharvest treatment to maintain postharvest organic table grape quality. Acta Horticulturae, 933, 621-625.

Celik, O. F., Demirkol, M., Durmus, Y., \& Tarakci, Z. (2020). Effects of drying method on the phenolics content and antioxidant activities of cherry laurel (Prunus laurocerasus L.). Journal of Food Measurement and Characterization, 14(1), 48-54.

Guillén, F., Díaz-Mula, H. M., Zapata, P. J., Valero, D., Serrano, M., Castillo, S., \& Martínez-Romero, D. (2013). Aloe arborescens and Aloe vera gels as coatings in delaying postharvest ripening in peach and plum fruit. Postharvest Biology and Technology, 83, 54-57.

Islam, A. (2002). 'Kiraz' cherry laurel (Prunus laurocerasus). New Zealand Journal of Crop and Horticultural Science, 30, $301-302$.

Islam, A., \& Deligöz, H. (2012). Selection on cherry laurel (Laurocerasus officinalis L.) in Ordu region. Akademik Ziraat Dergisi, 1(1), 37-44.

Kahramanoğlu, İ., Chen, C., Chen, J., \& Wan, C. (2019). Chemical constituents, antimicrobial activity, and food preservative characteristics of Aloe vera gel. Agronomy, 9(12), 831.

Karadeniz, T., \& Kalkisim, O. (1996). A study on selection of promising native cherry laurel (Prunus laurocerasus L.) genotypes from Akcaabat, Turkey. Yuzuncu Yıl University Journal of Agricultural Sciences, 6, 147-153.

Kasim, R., Sülüşoğlu, M., \& Kasım, M. U. (2011). Relationship between total anthocyanin level and colour of natural cherry laurel (Prunus laurocerasus L.) fruits. African Journal of Plant Science, 5(5), 323-328.

Kolayli, S., Küçük, M., Duran, C., Candan, F., \& Dinçer, B. (2003). Chemical and antioxidant properties of Laurocerasus officinalis Roem. (cherry laurel) fruit grown in the Black Sea region. Journal of Agricultural and Food Chemistry, 51(25), $7489-7494$.

Martínez-Romero, D., Alburquerque, N., Valverde, J. M., Guillén, F., Castillo, S., Valero, D., \& Serrano, M. (2006). Postharvest sweet cherry quality and safety maintenance by Aloe vera treatment: a new edible coating. Postharvest Biology and Technology, 39(1), 93-100.

Ozturk, B., Celik, S. M., Karakaya, M., Karakaya, O., Islam, A., \& Yarilgac, T. (2017). Storage temperature affects phenolic content, antioxidant activity and fruit quality parameters of cherry laurel (Prunus laurocerasus L.). Journal of Food Processing and Preservation, 41(1), e12774.

Ozturk, B., \& Ozer, H. (2019). Effects of grafting and green manure treatments on postharvest quality of tomatoes. Journal of Soil Science and Plant Nutrition, 19(4), 780-792.

Ozturk, B., Karakaya, O., Yıldız, K., \& Saracoglu, O. (2019a). Effects of Aloe vera gel and MAP on bioactive compounds and quality attributes of cherry laurel fruit during cold storage. Scientia Horticulturae, 249, 31-37.

Ozturk, A., Yildiz, K., Ozturk, B., Karakaya, O., Gun, S., Uzun, S., \& Gundogdu, M. (2019b). Maintaining postharvest quality of medlar (Mespilus germanica) fruit using modified atmosphere packaging and methyl jasmonate. LWT-Food Science and Technology, 111, 117-124.

Selcuk, N., \& Erkan, M. (2014). Changes in antioxidant activity and postharvest quality of sweet pomegranates cv. Hicrannar under modified atmosphere packaging. Postharvest Biology and Technology, 92, 29-36.

Serrano, M., Martinez-Romero, D., Guillen, F., Castillo, S., \& Valero, D. (2006). Maintenance of broccoli quality and functional properties during cold storage as affected by modified atmosphere packaging. Postharvest Biology and Technology, 39(1), 61-68.

Steffens, C. A., Amarante, C. V. T., Espindola, B. P., Heinzen, A. S., Brackmann, A., \& Both, V. (2018). 'Laetitia' plums stored in controlled atmospheres combined with induction of mass loss and ethylene management. Revista Caatinga, 31(1), 225234.

Sulusoglu, M. (2011). The cherry laurel (Prunus laurocerasus L.) tree selection. African Journal of Agricultural Research, 6(15), 3574-3582.

Sulusoglu, M., \& Cavusoglu, A. (2009). Cutting propagation possibilities of natural cherry laurel (Prunus laurocerasus L.) of Turkey. American-Eurasian Journal of Sustainable Agriculture, 234-238.

Var, M., \& Ayaz, F. A. (2004). Changes in sugar composition in cherry laurel (cv oxygemmis) fruit during development and ripening. Pakistan Journal of Botany, 36(2), 389-394.

Vargas, M., Pastor, C., Chiralt, A., McClements, D. J., \& Gonzalez-Martinez, C. (2008). Recent advances in edible coatings for fresh and minimally processed fruits. Critical Reviews in Food Science and Nutrition, 48(6), 496-511. 
Vieira, J. M., Flores-López, M. L., de Rodríguez, D. J., Sousa, M. C., Vicente, A. A., \& Martins, J. T. (2016). Effect of chitosan-Aloe vera coating on postharvest quality of blueberry (Vaccinium corymbosum) fruit. Postharvest Biology and Technology, 116, 88-97.

Yazici, K., Çakir, B., \& Kazaz, S. (2011). important genetic resource for Turkey: cherry laurel (Laurocerasus officinalis Roemer). Acta Horticulturae, 890, 261-265

Zhang, M., De Baerdemaeker, J., \& Schrevens, E. (2003). Effects of different varieties and shelf storage conditions of chicory on deteriorative color changes using digital image processing and analysis. Food Research International, 36(7), 669-676. 